\title{
Scale Effects on Conventional and Intercooled Turbofan Engine Performance
}

\author{
Andrew Rolt, Vishal Sethi, Florian Jacob, Joshua Sebastiampillai \\ corresponding author email: a.rolt@cranfield.ac.uk \\ Cranfield University, \\ Bedfordshire, MK43 OAL, UK \\ Carlos Xisto, Tomas Grönstedt \\ Chalmers University of Technology, \\ Göteborg, Sweden \\ Lorenzo Raffaelli \\ Rolls-Royce plc, \\ Derby, Derbyshire, DE24 8BJ, UK
}

\begin{abstract}
New commercial aero engines for 2050 are expected to have lower specific thrusts for reduced noise and improved propulsive efficiency, but meeting the ACARE Flightpath 2050 fuel burn and emissions targets will also need radical design changes to improve core thermal efficiency. Intercooling, recuperation, inter-turbine combustion and added topping and bottoming cycles all have the potential to improve thermal efficiency.

However, these new technologies tend to increase core specific power and reduce core mass flow, giving smaller and less efficient core components. Turbine cooling also gets more difficult as engine cores get smaller. The core-size-dependent performance penalties will become increasingly significant with the development of more aerodynamically efficient and lighter-weight aircraft having lower thrust requirements.

In this study the effects of engine thrust and core size on performance are investigated for conventional and intercooled aero engine cycles. Large intercooled engines could have 3-4\% SFC improvement relative to conventional cycle engines, while smaller engines may only realize half of this benefit. The study provides a foundation for investigations of more complex cycles in the EU Horizon 2020 ULTIMATE programme.
\end{abstract}

Keywords: Horizon 2020; ULTIMATE; Flightpath 2050; Propulsion. 


\section{NOMENCLATURE}

ACARE
Booster
CCA
CCACA
CLEAN
Core
EPA
HP
IATA
ICAO
IP
ISA
LEMCOTEC
LP
NEWAC
NO
Open Rotor
OPR
Propulsion System
Propulsor
SFC
$T_{3}$
$T_{c}$
$T_{\text {cref }}$
$T_{\text {gref }}$
$T_{\text {grel }}$
TET
ULTIMATE
VITAL
$W_{4}$
$W_{4 r e f}$
$W_{c}$
$W_{\text {cref }}$

Advisory Council for Aerospace Research in Europe

An IP compressor driven in a fixed speed relationship to the fan

Cooled cooling air

Cooled cooling air cooling air

Component Validator for Environmentally Friendly Aero Engine

Those parts of the engine that generate power for propulsion

Environmental Protection Agency

High Pressure

International Air Transport Association

International Civil Aviation Organisation

Intermediate Pressure

International Standard Atmosphere

Low Emissions Core Engine Technologies

Low Pressure

New Aero-engine Core Concepts

Oxides of nitrogen

A high-speed propulsor or propulsion system with one or two propeller blade rows Overall Pressure Ratio

All the components needed to provide thrust, integrated for the aircraft

A fan, propeller, open rotor or other thrust producing device

Specific Fuel Consumption

HP compressor exit temperature

HP cooling air temperature

Reference engine HP cooling air temperature

Reference engine gas relative inlet temperature for HP turbine first stage

Gas relative inlet temperature for HP turbine first stage at design point

Turbine Entry Temperature

Ultra Low Emissions Technology Innovations for Mid-century Aircraft Turbine Engines

Environmentally Friendly Aero Engine

Combustor exit mass flow

Reference engine combustor exit mass flow

HP cooling air mass flow

Reference engine HP cooling air mass flow

\section{Symbols}

$\delta$

$\lambda$
Correction to HP compressor polytropic efficiency

HP compressor last stage blade height

\subsection{INTRODUCTION}

Long-range commercial aircraft in 2050 are expected to have geared-fan engines, while short-range aircraft, cruising slightly slower, may use open rotors [1]. The high bypass ratio ducted fan engines could have variablepitch fan blades as an enabler to reduce specific thrust and increase propulsive efficiency. The open rotor engines could have a pusher configuration with very efficient contra-rotating blades. Nevertheless, these engines will not meet the ambitious ICAO, IATA, NASA, EPA and ACARE fuel burn targets for aero engines without radical developments in engine cores to improve thermal efficiency. This is because further increases to overall pressure ratio (OPR) and turbine entry temperature (TET), in the currently used open-circuit Brayton cycle, give diminishing returns. Limiting combustor entry and exit temperatures will also limit $\mathrm{NO}_{\mathrm{x}}$ emissions.

The EU Horizon 2020 ULTIMATE programme [2,3] investigates breakthrough technologies for aircraft propulsion to meet ACARE 'Flightpath 2050' targets for $\mathrm{CO}_{2}$, noise and emissions [4]. It reviews the potential benefits of combinations of intercooling, recuperation, inter-turbine combustion, and topping and bottoming cycles. These technologies have the potential to give step-change improvements in core thermal efficiency. However the technologies also tend to reduce core engine mass flow and core size, which can offset some of the benefits by reducing component efficiencies. 


\subsection{Aircraft and Propulsion Systems for $\mathbf{2 0 5 0}$}

Regarding airframes for 2050 entry into service, the ULTIMATE project includes studies of two advanced "tube and wing" configured aircraft. These will provide thrust requirements for more detailed engine design studies and facilitate holistic engine assessments over complete flight missions. The airframes are an intra-European aircraft with twin open rotor powerplants, and an inter-continental aircraft with two turbofan engines. However, the thrust requirements are not defined at the time of writing, so reference turbofan engine thrusts are taken from the previous EU Framework 6 research programme NEWAC [5, 6]. Factors influencing the choice of propulsor configuration include: initial cost, maintenance cost, weight, propulsive efficiency, nacelle drag, ease of installation, noise and reverse thrust requirements.

Open rotor powerplants can have one or two propeller blade rows in either tractor or pusher configuration. The second contra-rotating blade row straightens out the swirl from the first rotor, increasing overall efficiency. This also enables quieter, lower tip-speed propellers to be used. Low noise is essential if open rotor powerplants are to be adopted on future medium sized commercial aircraft. For these aircraft the pusher arrangement, with engines mounted on pylons either side of the aft fuselage, is preferred. This installation minimizes cabin noise provided the core exhaust is ducted around the rotor hubs, rather than impinging on the propeller blades in the open air. A further advantage of the pusher arrangement is that the propulsor drive-shafts do not need to run through the core of the engine and so do not compromise its design. Nevertheless the tractor arrangement may be preferred for wing mounted engines on lower speed aircraft. In this case a reverse flow core arrangement, like that of the Pratt \& Whitney PT6 turboprop, should avoid compromising the turbomachinery design.

Contra-rotating open rotors offer significant fuel burn reductions from increased propulsive efficiency and reduced nacelle drag, but they are less attractive for larger aircraft wanting higher cruise speeds for longer flights. The current study does not model open rotor engine configurations, but it does consider the effects of scaling down the thrust requirements for the turbofan to levels where the core mass flow would be appropriate for an open rotor propulsion system.

Reverse thrust is a requirement for most commercial aircraft, because it provides an effective means of stopping them on icy runways. Turboprops and open rotor engines with variable-pitch blades can provide reverse thrust at relatively little cost or weight penalty, but conventional thrust reverser designs for large turbofan engines come with significant penalties. They add cost, weight and drag, and are a disincentive to the development of engines with larger fans for increased propulsive efficiency. In this study it is assumed the turbofan engines all have variable-pitch fans with capability to provide reverse thrust if needed. All the engines are modelled with the same low cruise specific thrust that ULTIMATE industry partners considered likely to be feasible by 2050 . Ground clearance is a possible restriction on fan diameter for under-wing mounted engines, but no constraint is applied in the current study because the thrust requirements for the 2050 long-range aircraft should be significantly reduced by airframe and engine weight savings and efficiency improvements.

\subsection{Intercooled Engines}

In intercooled turbofan engines, part of the fan bypass air-flow is used to cool the intermediate pressure (IP) compressor delivery air before this enters the high pressure (HP) compressor. This engine arrangement was studied in NEWAC and is shown schematically in Fig. 1. NEWAC showed that high OPR intercooled cores, or intercooled and recuperated cores, should reduce SFC and $\mathrm{NO}_{\mathrm{x}}$ emissions. However, the required heat exchangers add weight and drag to these propulsion systems, offsetting much of the potential fuel burn benefit [6]. Some rig tests have been carried out, but intercooling has not yet seen full engine demonstration.

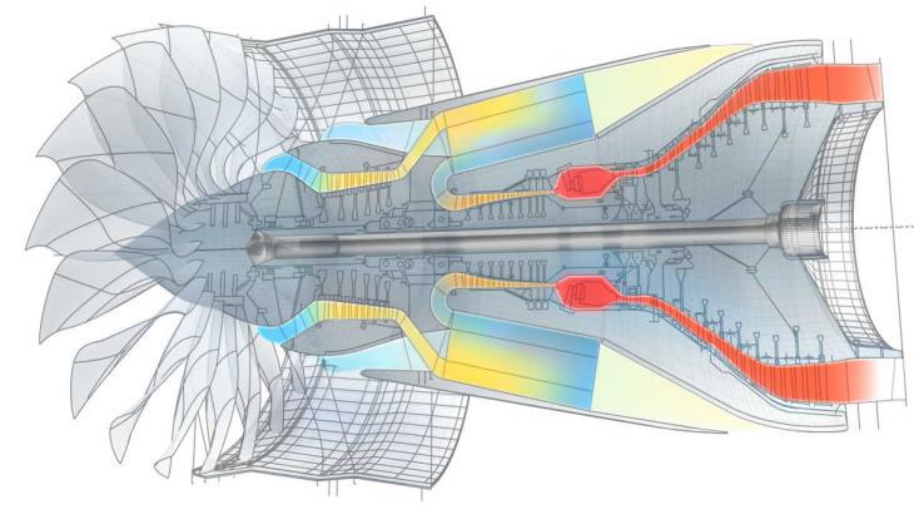

Figure 1 Schematic diagram of an intercooled engine with a low-speed LP turbine and a direct-drive fan 
Intercooling reduces compression work by reducing the inlet air temperature for the HP compressor and the volume flow rate of air passing through it, enabling increased OPR without raising HP compressor delivery air temperatures $\left(\mathrm{T}_{3}\right)$ to very high levels. It also reduces annulus cross-section areas in the HP system, saving some weight, but by reducing blade heights it also reduces core component efficiencies.

Small blade height at the back of the HP compressor was a major issue for intercooled engine designs in the NEWAC programme. The original three-shaft study engines had fans directly driven by the low-speed low pressure (LP) turbines via high-torque shafts. The LP and IP system shafts passed through the central bores of the HP spools, imposing minimum bore diameters and limiting HP rotational speeds. Thus the HP turbomachinery could not be scaled down very much in diameter and it needed to have higher hub/tip radius ratio blading, giving significantly smaller blade heights and reduced component efficiencies.

This problem was alleviated in a later NEWAC study by having a geared fan driven by a high-speed turbine. The lower torque and smaller diameter shaft also drove the IP compressor or "booster", eliminating the need for a separate IP turbine and its shaft. This enabled a faster-running smaller-diameter HP system with increased blade heights, lower hub/tip radius ratios and notably improved compressor efficiency [7].

A reverse flow core intercooled turbofan was investigated in the more recent LEMCOTEC programme [8]. This arrangement is shown schematically in Fig. 2. By placing the fan, IP compressor and turbines in front of the HP compressor, the HP system no longer needs to have other shafts passing through it [9]. HP compressor efficiency is improved and the optimum OPR is increased, but following reassessment of the exhaust mixer performance and ducting losses it was concluded that the improvements in SFC and fuel burn from this architecture were only about one per cent [10].

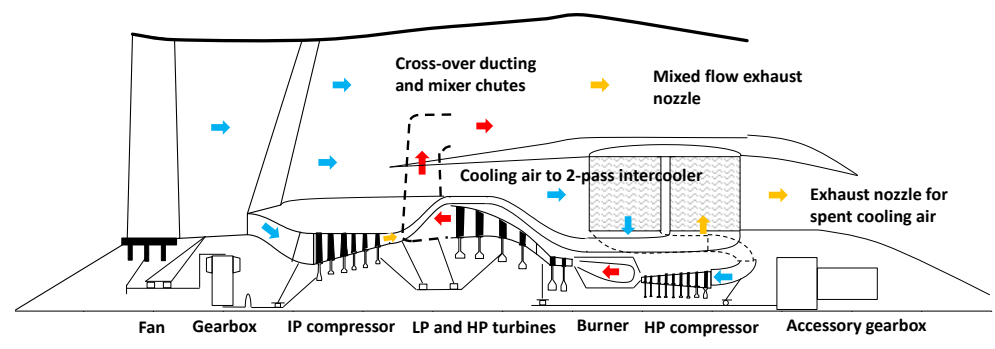

Figure 2 Schematic diagram of a reverse flow core intercooled turbofan aero engine arrangement

The reverse flow core arrangement is an option for novel cycles with core components that may not integrate so well into the more conventional straight-through-flow and front-fan turbofan engine layout, but development of improved materials for discs and shafts may reduce the small performance benefit that it currently offers. In the current study it is assumed that smaller core designs will not be penalised by large LP shaft diameters.

\subsection{Variable-cycle Capability}

Variable geometry components can improve off-design performance and operability. Figure 3 shows the RollsRoyce UltraFan ${ }^{\mathrm{TM}}$ concept having a variable-pitch geared fan driven by a high-speed turbine. This arrangement has an inherent capability to vary the work-split between core compression and the fan's bypass section.

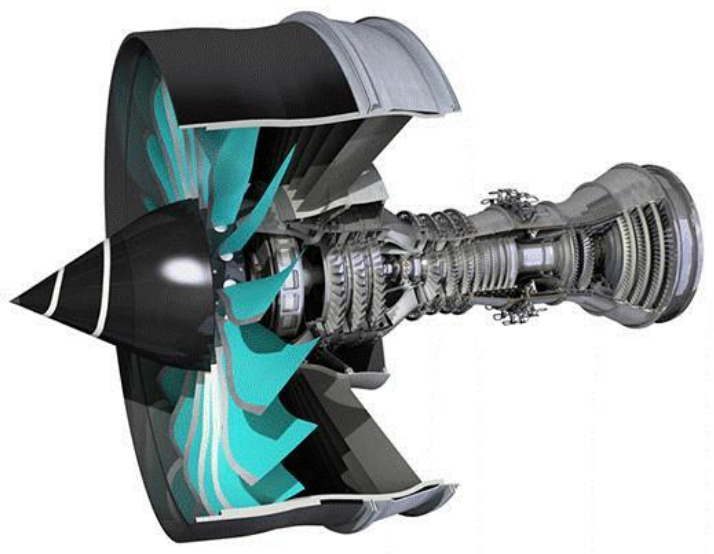

Figure 3 Rolls-Royce UltraFan ${ }^{\mathrm{TM}}$ engine concept having a variable-pitch geared fan 
Low specific thrust engines with low fan pressure ratios have un-choked bypass exhaust nozzles at takeoff. This means fan mass flow is relatively reduced at low flight Mach numbers, risking either fan surge or flutter at takeoff, or compromising fan efficiency at cruise and top of climb. These problems can be avoided with a variable-area cold flow exhaust nozzle, or by having variable-pitch fan rotor blades. For the very low specific thrust turbofan engines anticipated for 2050, one or both of these solutions is likely to be needed. The variablepitch fan also holds out the prospect of providing reverse thrust without a conventional thrust reverser, though an auxiliary intake may be needed to provide reliable thrust reversal at higher forward speeds. Avoiding the extra weight and extra nacelle drag associated with conventional thrust reversers means that optimised designs can benefit from lower specific thrust and higher propulsive efficiency.

Part of the benefit from intercooling, or from intercooling and recuperation, also comes from creating variablecycle engines. In intercooled engines, maximizing intercooling at takeoff reduces combustor and turbine temperatures and enables reduced core size and lower $\mathrm{NO}_{\mathrm{x}}$ emissions. At climb and cruise conditions the amount of cooling air for the intercooler can be reduced, raising core cycle temperatures to improve thermal efficiency while also reducing pressure losses on the cold side of the heat exchanger. It may also be possible to reduce hot side pressure losses at cruise conditions by allowing part of the core flow to bypass the intercooler [11], though no benefit has been claimed for this in the current performance modelling.

Variable-cycle capability introduces extra degrees of freedom in the optimisation of engine performance and needs to be taken into consideration when comparing different cycle options at the concept design stage.

\subsection{Engine Cycle Studies}

The ULTIMATE design studies review combinations of core engine technologies to identify synergies between them. Engine performance in the current study is compared at typical mid-cruise, max climb and max takeoff conditions. Consistent rules are applied for component efficiencies, temperature limits and turbine cooling flows. This paper covers the anticipated performance of conventional and intercooled engines for mid-century entry into service. Subsequent papers will review other advanced technologies, component designs, and novel engine architectures to fully realize the potential of advanced cycles to reduce SFC, fuel burn and $\mathrm{NO}_{\mathrm{x}}$ emissions. It is assumed that engines in 2050 will still run on kerosene or drop-in replacement bio-fuels. The use of different fuels may well affect future engine designs, but is beyond the scope of the current studies.

\subsection{METHODOLOGY}

In this study a simplified approach is taken to cycle modelling, with stream-tube thrust requirements fixed at the three key flight conditions shown in table 1. The reference thrust levels are based on those used in the previous EU programmes VITAL and NEWAC for a long-range twin-engined aircraft [6]. Aircraft accessory power is taken from the HP spool, but no compressed air is supplied to the aircraft. For scaled engines the thrusts and power offtakes at each condition are scaled by a common thrust scale factor.

Table 1

Initial Long-range Aircraft Thrust Requirements (per engine)

$\begin{array}{lccc} & \text { Mid-Cruise } & \text { Max Climb } & \text { Max Takeoff } \\ \text { Altitude (ft) } & 35,000 & 35,000 & 0 \\ \text { Altitude (m) } & 10,668 & 10,668 & 0 \\ \text { Mach Number } & 0.82 & 0.82 & 0.25 \\ \text { Deviation from ISA } & 0^{\circ} \mathrm{C} & 10^{\circ} \mathrm{C} & 15^{\circ} \mathrm{C} \\ \text { Net Thrust }(\mathrm{kN}) & 49 & 67 & 253 \\ \text { Power Offtake }(\mathrm{kW}) & 260 & 260 & 260\end{array}$

The reference engine for the study is a conventional Brayton cycle turbofan with component efficiencies, materials, OPR and operating temperatures projected forwards to year 2050 entry into service. Similar to Fig. 3, it has the following key features:

- A geared variable-pitch fan and a high speed booster driven by a high-speed turbine

- Fixed area separate jet exhaust nozzles

- An all-axial HP compressor driven by a two-stage HP turbine

- Cooled cooling air for cooling the HP system

- High OPR and very low specific thrust, giving bypass ratios in excess of twenty 
The reference engine was sized initially for a long-range aircraft of around 240 tonnes maximum takeoff weight, and engine performance was assessed with component efficiencies, materials and blade cooling technologies projected forwards to the year 2050. Takeoff performance is quoted for a hot day end-of-runway case, so the static takeoff thrust would be higher.

The intercooled engines have the same geared fan arrangement as Fig. 3, but with intercooler modules positioned as shown in Fig. 1. These modules may now have a two-pass cross-flow arrangement [11]. Their spent cooling air is assumed to be ducted to separate variable area exhaust nozzles, rather than being mixed back into the main bypass duct. The reverse flow core and mixed exhaust arrangement of Fig. 2 has not been modelled in the current study, but remains a future option. It has the potential to further reduce noise and improve SFC and fuel burn, for both the conventional and intercooled engine cycles.

Spreadsheet performance models are used to compare different cycle options and varying thrust requirements. The spreadsheets use equations and polynomials for fluid properties taken from Walsh and Fletcher [12], pages 113-119. Component efficiencies are specified at design and off-design conditions. As only high power conditions are modelled, the turbines are assumed to be choked at inlet, component performance maps are not needed and cycle optimisation is simplified. Nacelle drags and afterbody drags are not assessed at this stage because they will depend on engine lengths and nacelle designs that will only be determined in more detailed design studies later in the ULTIMATE programme.

\subsection{Scaled Engine Design Assumptions}

Base-level polytropic efficiencies are specified at the above three flight conditions, but a scale correction is added to the HP compressor and HP turbine efficiencies to account for tip-clearance effects. The HP compressor has the smallest blades and is the turbo-machine subject to the biggest changes in efficiency when it is scaled. The models assume all-axial compression systems and use the polytropic efficiency correction from a previous study of intercooled engines [7], but a new correlation provides an improved curve fit for the efficiency correction $\delta$ as a function of the last blade height $\lambda(\mathrm{mm})$. This is specified by equation (1).

$$
\delta=0.0532-0.5547\left(\frac{1}{\lambda}\right)-1.7724\left(\frac{1}{\lambda^{2}}\right)
$$

Ideally, the efficiency correction would be recalculated for any changes in HP compressor design pressure ratio, hub/tip radius ratio etc. However, equation (1) is assumed to be representative for all the high pressure ratio HP compressors in the current study. Figure 4 compares equation (1) with the original efficiency correction curve.

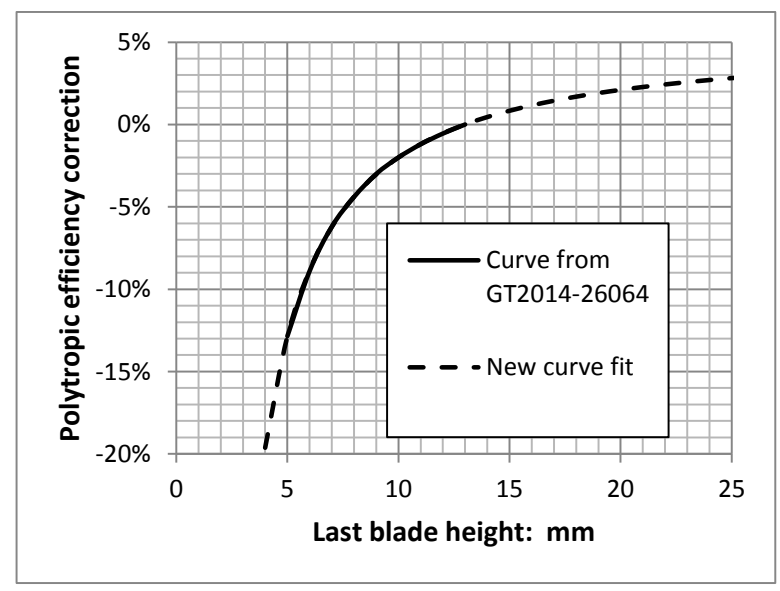

Figure 4 HP Compressor Correction to Polytropic Efficiency

The HP compressor last stage blade height is calculated at the design point condition based on an exit hub/tip ratio of 0.925 and an exit axial Mach number of 0.254 at mid-cruise. These figures are for a high pressure ratio axial compressor driven by a two-stage HP turbine. All the engine cycles reported in this paper are assumed to have this HP system configuration, though the smallest cores could use axi-centrifugal compressors instead.

Ideally the scale corrections should account not only for over-tip leakage losses, but also for other secondary flows, blade thickness/chord ratios and Reynolds number effects. The assumption that all cores can have the same hub/tip ratios may also be optimistic and perhaps dependent on the reverse-flow core arrangement. In these respects the corrections may be under-estimated. On the other hand, better control of tip-clearances may be achieved by 2050. Thus there is considerable uncertainty over the appropriate magnitude of the corrections. 
The scale corrections for HP turbine polytropic efficiency are, for simplicity, taken to be half as large as the compressor efficiency corrections. No corrections are applied to the LP turbomachinery components, which are expected to show smaller efficiency variations with scaling. Those changes would mostly affect transfer efficiency and have little effect on the core thermal efficiency that is of greater interest in these studies.

\subsection{Cooling Requirements}

The 2050 reference turbofan has higher $\mathrm{T}_{3}$ and TET than existing engines, so it uses cooled cooling air (CCA) to cool the HP system and to reduce the amount of cooling air required. The CCA system is designed such that sufficient cooled cooling air cooling air (CCACA) is taken from the bypass duct through a heat exchanger to bring the CCA temperature $\left(T_{c}\right)$ down to $900 \mathrm{~K}$ when $\mathrm{T}_{3}$ is hotter than this. Pre-swirling the air ahead of the first HP turbine rotor is assumed to compensate for heat pick-up prior to blade cooling. Both the CCA heat exchanger and the intercooler eject spent cooling air overboard through dedicated variable-area exhaust nozzles that help to recover thrust.

Cooling the CCA is generally unnecessary at cruise, so there the CCACA flow is zero. The intercooled engines still benefit from CCA at takeoff, but the system is hardly needed for the lowest $\mathrm{T}_{3}$ cycles. For each engine design, the off-design CCA mass flow, whether pre-cooled or not, is a fixed percentage of the core mass flow.

Detailed modelling of secondary air systems is beyond the scope of this study, but it is recognised that scaling down the HP core components makes cooling them more difficult. Thus all design point HP CCA mass flows are scaled from the $6 \%$ of core flow assumed for the reference turbofan. Scaling accounts for two factors:

- Changes in HP turbine design point mass flow

- Temperature differences between the HP turbine first blade row relative inlet gas temperature $\left(T_{\text {grel }}\right)$ and the blade cooling air temperature $\left(T_{c}\right)$

The relative gas temperature is calculated as corresponding to $25 \%$ of the temperature drop through the twostage HP turbine, assuming 50\% reaction blading and equal temperature drops through both stages. The HP cooling air flow for a given design point $\mathrm{T}_{3}$ and TET is assumed to vary with the ratio of core mass flow raised to the power of 0.65 . This figure is a compromise between an index of 0.8 , obtained by assuming the convective heat transfer coefficients are limiting, and an index of 0.5 , which applies if the heat flux is proportional to the thermal gradients in geometrically scaled components. In practice thermal barrier coating thicknesses etc. will not exactly scale. Smaller engines will also tend to have lower aspect ratio blading, so engine length and diameter will scale at different rates. The two scaling factors are combined in equation (2):

$$
W_{c}=\frac{W_{\text {cref }}\left(T_{\text {grel }}-T_{\text {cref }}\right)\left(W_{4} / W_{4 r e f}\right)^{0.65}}{\left(T_{\text {gref }}-T_{c}\right)}
$$

The same HP cooling air mass flow scaling rule is applied to both conventional and intercooled engine cycles. Lower pressure cooling and sealing air flows, assumed to be just $2 \%$ of core mass flow, are not scaled.

\subsection{Heat Exchanger Design Constraints}

Further assumptions need to be made in order to model the heat exchangers. Practical intercooler effectiveness is limited by the trade-off between higher effectiveness on the one hand, and higher cost, weight, nacelle drag and pressure losses on the other hand. Table 2 shows how the heat exchanger effectiveness levels and pressure losses are limited in the models. These figures are based on experience from earlier studies in NEWAC and LEMCOTEC, but with allowance for anticipated heat exchanger performance improvements by 2050 . The pressure losses in table 2 are additional to the duct losses in the reference turbofan cycle model.

Table 2

Heat Exchanger Performance Assumptions

\author{
Intercooler: \\ Max effectiveness (hot side) \\ Hot side pressure loss \\ Cold side pressure loss \\ Cooling air mass flow ratio \\ CCA cooler: \\ Max effectiveness (cold side) \\ Hot side pressure loss \\ Cold side pressure loss
}

\section{Mid-Cruise}

$50-69 \%$
$5 \%$
$3-6 \%$
$0.8-1.1$

$-$

$1 \%$
Max Climb

$75 \%$

$6 \%$

$7 \%$

1.2

$75 \%$

$1 \%$

$5 \%$
Max Takeoff

$70 \%$

$5 \%$

$10 \%$

1.5

$70 \%$

$1 \%$

$20 \%$ 
Note the heat exchanger effectiveness figures are for "temperature effectiveness", defined as the difference between the inlet and outlet temperatures on the side of interest, divided by the difference between the overall maximum and minimum air temperatures entering and exiting the heat exchanger.

The intercooler cooling air mass flow ratio is the ratio of cold-side to hot-side mass flow. The off-design cooling air flow is adjusted using the variable-area exhaust nozzles that recover thrust from the spent cooling air. The intercooler cooling air mass flow is typically kept relatively low at cruise to reduce heat loss from the core and to minimise pressure losses and thus SFC, but it is increased at takeoff to limit $\mathrm{T}_{3}$ and TET.

The mass flow ratio of CCACA to CCA is adjusted at each condition to ensure that there is sufficient CCACA mass flow to limit the cold side of the heat exchanger to $75 \%$ effectiveness at climb and $70 \%$ at takeoff. This minimises the size of the heat exchanger and limits the temperature of the spent cooling air. The hot side loss in the CCA heat exchanger is low because this air flow has the highest density and heat transfer coefficients even at relatively low Mach numbers. Also it does not suffer from any extra diffuser losses.

\subsection{Cycle OPR and Temperature Limits}

To make a fair comparison between the intercooled cycles and the reference engine, the latter's hot day takeoff $\mathrm{T}_{3}$ and TET values are taken as limiting values. The HP compressor pressure ratio is taken to be limited by the maximum power realistically available from the two-stage HP turbine, or to 26:1 at the max climb condition.

In modelling the scaled and intercooled cycles some trade-offs between the mid-cruise and max climb TET and $\mathrm{T}_{3}$ are allowed, relative to the original reference engine cycle. When scaling the core, the OPR for a given $\mathrm{T}_{3}$ varies because of the HP compressor efficiency changes. The assumed temperature limits for mid-cruise, max climb and max takeoff are given in table 3.

Table 3

General Cycle Temperature Limits

$\begin{array}{lccc} & \text { Mid-Cruise } & \text { Max Climb } & \text { Max Takeoff } \\ \text { TET }(\mathrm{K}) & 1700 & 1890 & 1950 \\ \text { T3 }(\mathrm{K}) & 913 & 993 & 1063 \\ \text { Deviation from ISA } & 0^{\circ} \mathrm{C} & 10^{\circ} \mathrm{C} & 15^{\circ} \mathrm{C}\end{array}$

The larger engines benefit from working up to the maximum $\mathrm{T}_{3}$ and TET. The smaller engines also generally benefit from this, but see relatively smaller penalties from reducing OPR and $\mathrm{T}_{3}$. Reducing OPR should save weight. Reducing OPR, $\mathrm{T}_{3}$ or TET will also tend to reduce cost and $\mathrm{NO}_{\mathrm{x}}$ emissions.

\subsection{CYCLE MODELS}

\subsection{Reference Turbofan Cycle for 2050}

The performance modelled for the reference Brayton cycle turbofan for 2050 entry into service is summarised in table 4. The design points match the requirements of table 1 and a general consensus on projected technology developments provided by ULTIMATE consortium industry partners.

Table 4

Reference 2050 Turbofan Performance

$\begin{array}{lccc} & \text { Mid-Cruise } & \text { Max Climb } & \text { Max Takeoff } \\ \text { TET (K) } & 1580 & 1890 & 1950 \\ \text { T3 }(\mathrm{K}) & 880 & 992 & 1063 \\ \text { OPR } & 64.4 & 75.0 & 62.0 \\ \text { HP compressor ratio } & 20.0 & 25.9 & 23.2 \\ \text { Fan bypass pressure ratio } & 1.33 & 1.43 & 1.34 \\ \text { Bypass ratio } & 20.7 & 20.4 & 20.0 \\ \text { Specific thrust (m/s) } & 72 & 95 & 157 \\ \text { SFC (mg/N.s) } & 12.9 & 13.9 & 8.7\end{array}$

The cycle temperatures and overall pressure ratios may appear to be only a little more aggressive than those targeted in LEMCOTEC for 2025-2030 entry into service, but there are important differences in the core engine designs. The ULTIMATE reference engine assumes ceramic matrix composite turbine stator blades and improved turbine annulus sealing that greatly reduces the required secondary air system flows. The deletion of film cooling in the HP turbine statics improves aerodynamic efficiency. Restricting increases in OPR and $\mathrm{T}_{3}$ saves cost and weight and maintains more respectable blade heights to maximize HP compressor and turbine 
efficiency. Another benefit of restricting OPR and TET is that it avoids the combination of very high combustor inlet pressures and temperatures that would tend to increase flame temperatures and $\mathrm{NO}_{\mathrm{x}}$ emissions at takeoff, even with advanced lean-burn combustor technology.

Component designs are assumed optimised for the mid-cruise condition, so they are sub-optimal at top of climb and at takeoff. Table 5 shows the component polytropic efficiency penalties being applied at those off-design conditions. These are consistent with the thrusts and cycle temperatures given in tables 1 and 3 . The basic HP turbine efficiency is assumed to be constant, but the HP turbine and HP compressor efficiencies change when the core is scaled. (The combined fan root section and IP compressor is referred to as the LP compressor.)

Table 5

Reference 2050 Turbofan Off-design Component Polytropic Efficiency Variation

$\begin{array}{lccc} & \text { Mid-Cruise } & \text { Max Climb } & \text { Max Takeoff } \\ \text { Fan bypass stage } & \text { datum } & -2.2 \% & -0.7 \% \\ \text { LP compressor } & \text { datum } & -1.0 \% & -0.4 \% \\ \text { HP compressor } & \text { datum } & -3.8 \% & -1.7 \% \\ \text { LP turbine } & \text { datum } & -2.0 \% & -1.0 \%\end{array}$

These efficiency penalties in the reference turbofan model make the thermal efficiency worse at top of climb and at takeoff. They account for the worsening SFC at the high thrust end of the altitude SFC loop as shown in Fig. 5. The fan and compressor off-design efficiencies suffer because of high inlet Mach numbers at top of climb, which is a consequence of minimising weight by under-sizing components for this "corner of the envelope" condition where relatively little fuel is burned. The fan efficiency at climb and takeoff could be improved using variable-area exhaust nozzles, but these effects have not been modelled.

Before studying more advanced cycles, the reference turbofan was investigated to confirm that its cycle had been set up to give optimal performance. Figure 6 shows the effect of varying fan bypass pressure ratios, assuming nozzle areas are held constant between the cruise, climb and takeoff cases. It is clear that a fan bypass pressure ratio of 1.33 at mid-cruise gives very close to the optimum SFC at all three conditions. Figures close to these are used for all the models, since they all target the same mid-cruise specific thrust.

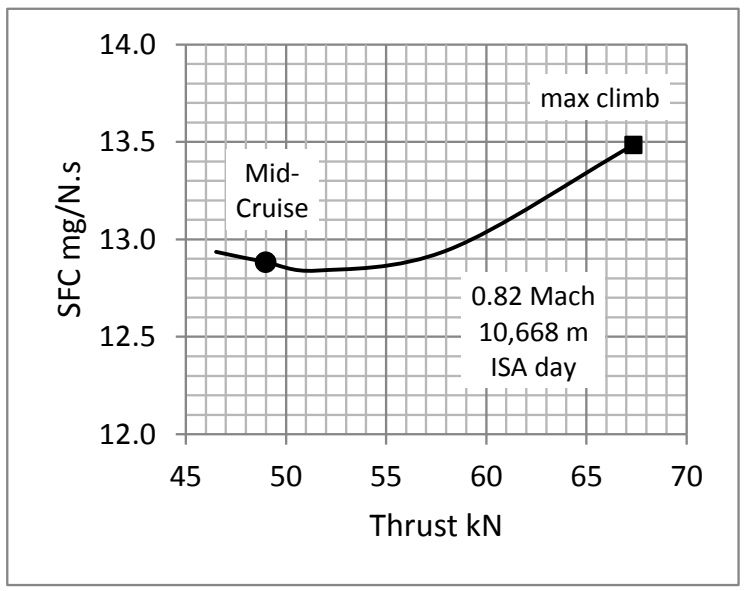

Figure 5 Reference 2050 turbofan SFC loop

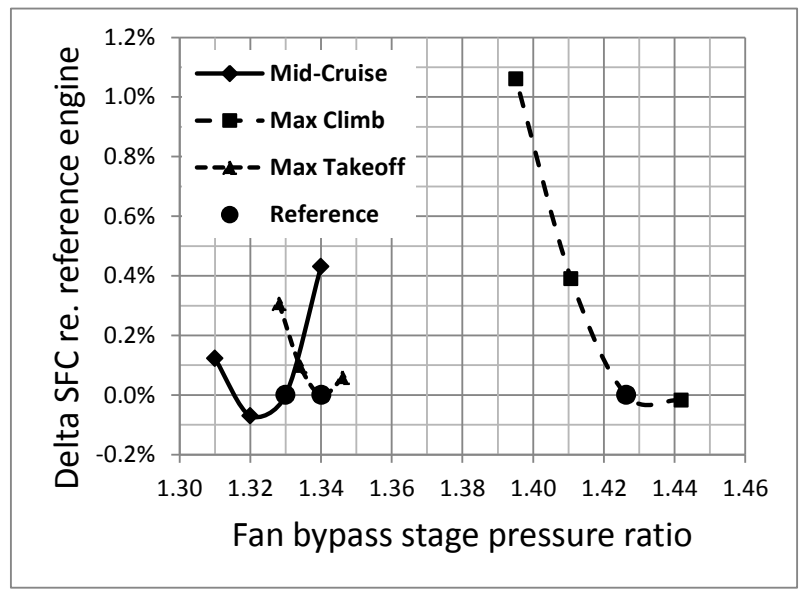

Figure 6 Effect of fan pressure ratio on SFC

Because the reference engine is assumed to have a variable-pitch fan and also variable stator vanes on its IP compressor, it is possible to vary the work-split between the core and bypass streams. Figure 7 shows how OPR and TET at the mid-cruise design point might be traded-off against each other. Assuming the component efficiencies stay constant when compressor pressure ratios change, the mid-cruise SFC hardly varies during this trade-off, as shown in Fig. 8. While constant component efficiency may be a reasonable assumption for small changes, it will not apply over the full range of compressor pressure ratios shown. The efficiency will depend on the detail design of the IP compressor and the number of variable stages. In practice small variations in work-split could be used to optimise overall compression efficiency throughout the flight envelope. Figure 9 shows the working line for the altitude SFC loop and how the mid-cruise working point could be repositioned along the dashed line by changing the trade-off between OPR and TET. 


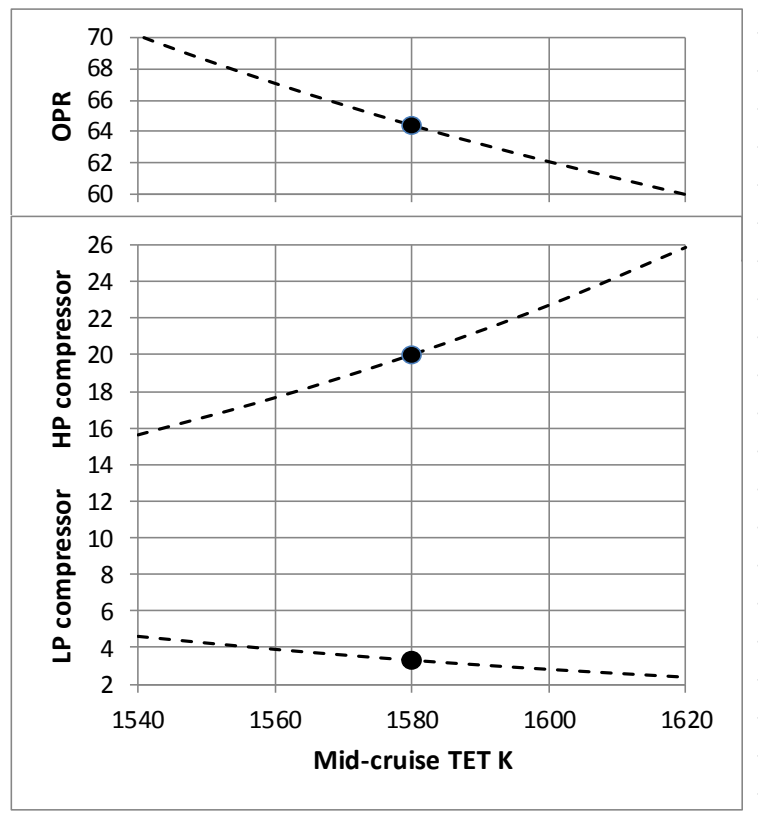

Figure 7 Effect on compressor pressure ratios of varying the fan/LP compressor work-split at cruise assuming constant compressor efficiencies

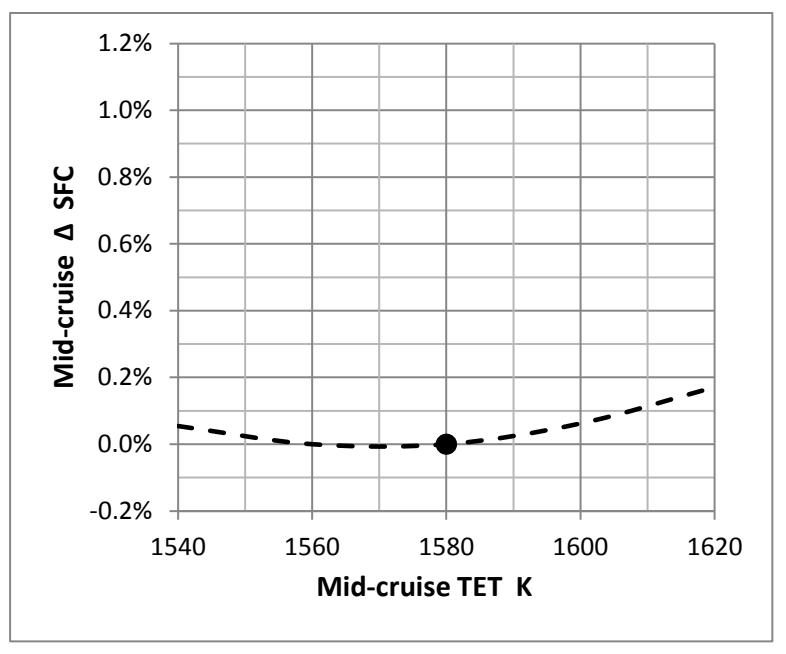

Figure 8 Effect on mid-cruise SFC of varying the fan/LP compressor work-split at constant component efficiency

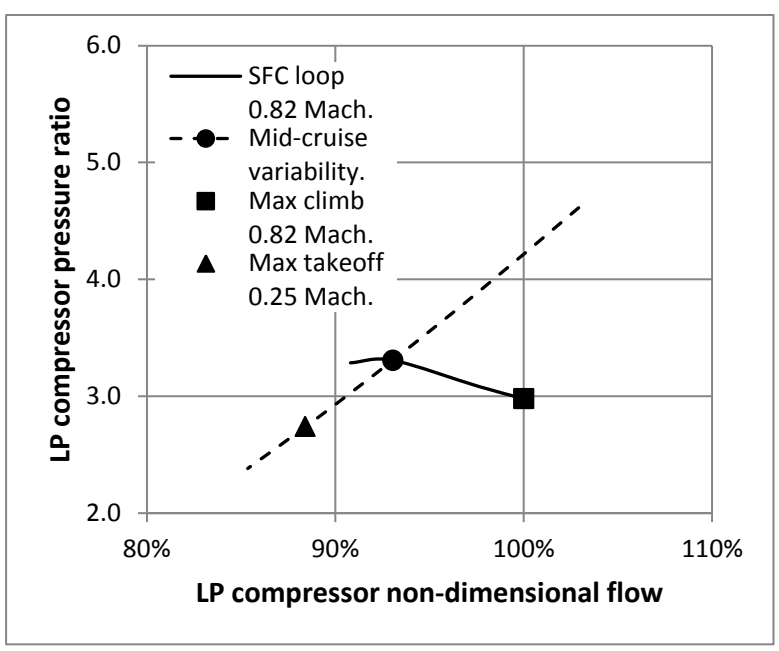

Figure 9 LP compressor altitude working line and the effect of varying the fan/LP compressor work-split

Thermal efficiency in the Brayton cycle tends to be maximised by increasing OPR and TET, but higher OPR reduces HP compressor last stage blade height, and higher $\mathrm{T}_{3}$ and TET require increased cooling air flows. Thus it is not obvious that maximising $\mathrm{T}_{3}$ and TET will always give the best SFC. However, Fig. 10 shows that for the component efficiency and cooling technology levels assumed for the reference turbofan, SFC is minimised by maximizing both $\mathrm{T} 3$ and TET at takeoff. Limiting $\mathrm{T}_{3}$ also limits OPR, and since all the engines in this study are designed for the same cruise specific thrust, varying the core mass flow also varies the bypass ratio. Bypass ratio is increased by increasing TET, or by reducing $\mathrm{T}_{3}$. Reducing TET or $\mathrm{T}_{3}$ increases the last HP compressor blade height, improving HP compressor efficiency and slightly increasing OPR for a given $\mathrm{T}_{3}$. Figure 11 shows the effects of reducing the max takeoff $\mathrm{T}_{3}$ and TET on the reference turbofan mid-cruise OPR and bypass ratio.

The high OPR cycles that have the highest takeoff and climb $T_{3}$ temperatures need to cool the CCA at takeoff and climb to $900 \mathrm{~K}$, as do the intermediate OPR cycles with $1010 \mathrm{~K} \mathrm{~T}_{3}$ at hot day takeoff, though in this case less CCACA mass flow is needed. The lowest OPR and $\mathrm{T}_{3}$ cycles only need to pre-cool the CCA air at takeoff conditions. The cycles do not need to use any CCACA at the ISA day mid-cruise condition because $\mathrm{T}_{3}$ remains below $900 \mathrm{~K}$. The mass flow of CCACA in the CCA heat exchanger is regulated according to the amount of pre-cooling required and the heat exchanger is sized to meet the max hot day takeoff cooling requirement. 


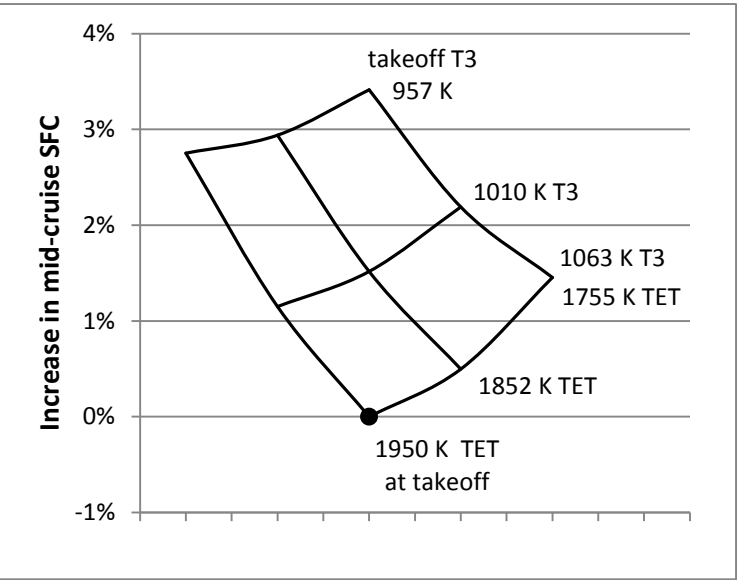

Figure 10 Effect of reducing hot day takeoff TET and $\mathrm{T}_{3}$ on the reference engine mid-cruise SFC

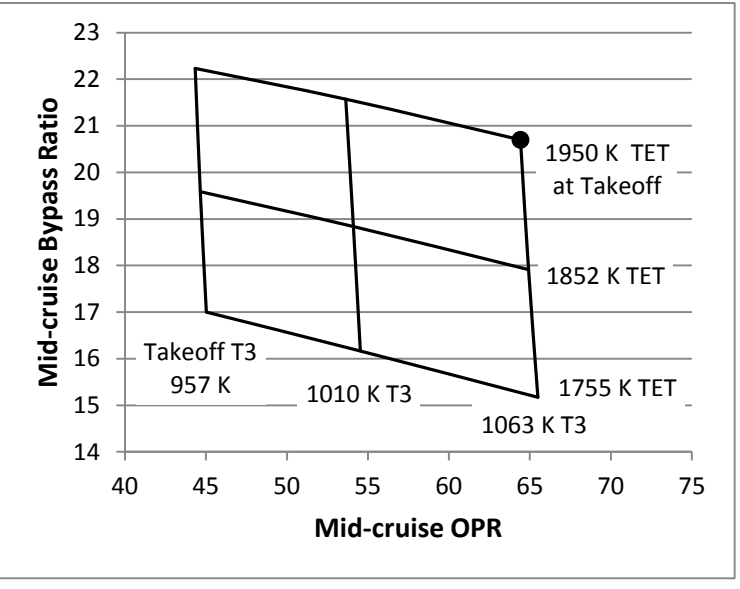

Figure 11 Effect of reducing hot day takeoff TET and $\mathrm{T}_{3}$ on the reference engine mid-cruise OPR and bypass ratio

\subsection{Scaling the Reference Turbofan Engine}

Figure 12 shows the effect of thrust scaling on mid-cruise SFC, when cruise, climb and takeoff thrusts are scaled pro rata. It also shows the effects of reducing $\mathrm{T}_{3}$ and TET on engines having different thrust scales. Specific thrust is held constant at the mid-cruise condition, so total engine mass flow is proportional to the thrust.

The ratio of CCA mass flow to core mass flow increases as the TET increases and as core mass flow reduces, as shown in Fig. 13. The ratio also increases when $\mathrm{T}_{3}$ reduces because this also reduces the core mass flow and because $T_{\text {grel }}$ increases when less work is demanded of the HP turbine. It is assumed that reducing $\mathrm{T}_{3}$ at climb and takeoff does not reduce $T_{c}$, but as $T_{3}$ reduces, the required CCACA mass flow reduces instead. Figure 13 also shows how the HP compressor last blade height varies. Core mass flow and HP compressor last blade height reduce as the thrust requirements reduce, or as TET increases. Conversely, the core mass flow and HP compressor last blade height increase when $\mathrm{T}_{3}$ and $\mathrm{OPR}$ increase.

Smaller blade heights reduce compressor efficiency, reducing OPR for a given $\mathrm{T}_{3}$ as shown in Fig. 14. The combined effects of reduced HP compressor and turbine efficiency, reduced OPR and the need for more cooling air, mean that the core thermal efficiency and specific power tend to reduce as thrust reduces. Figure 15 shows how bypass ratio varies: roughly in inverse proportion to core mass flow at fixed thrust and specific thrust.

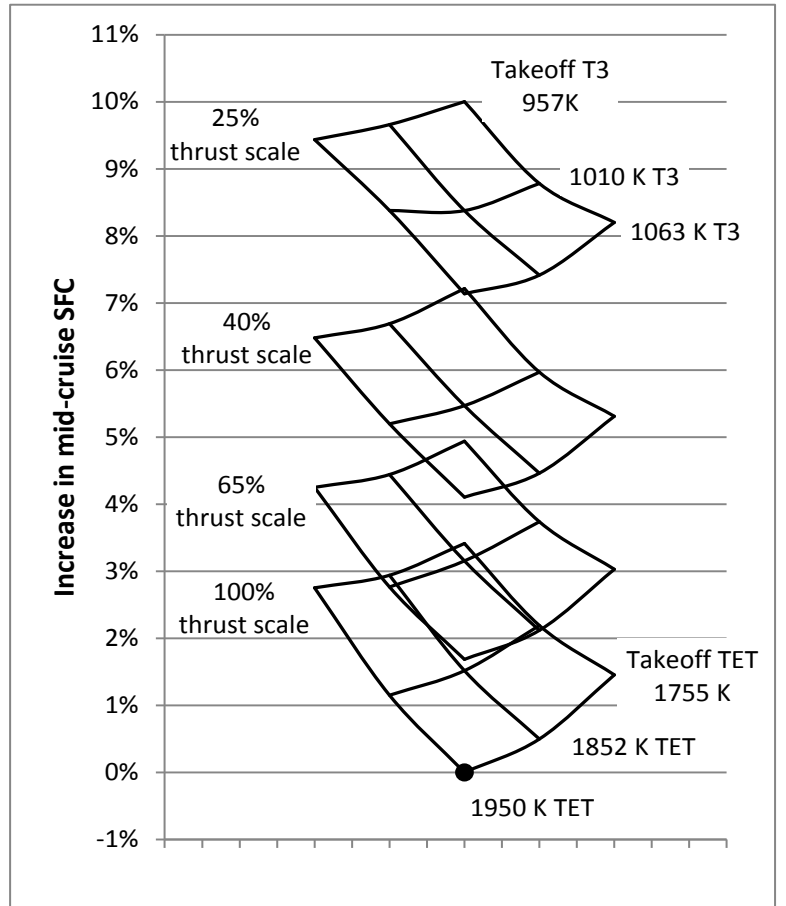

Figure 12 The effect on mid-cruise SFC of scaling the reference engine and designing it for various hot day takeoff temperature limits for $\mathrm{T}_{3}$ and TET

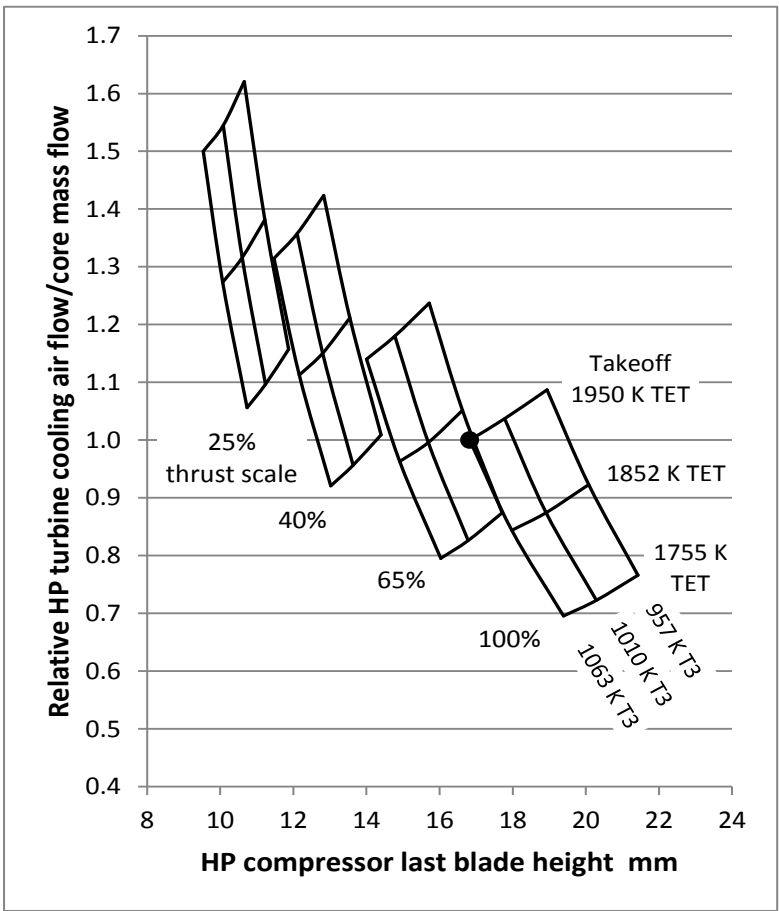

Figure 13 The effect on reference engine cooling flows of thrust scaling with different $\mathrm{T}_{3}$ and TET limits at hot day takeoff $\mathrm{v}$. HP compressor last blade height 


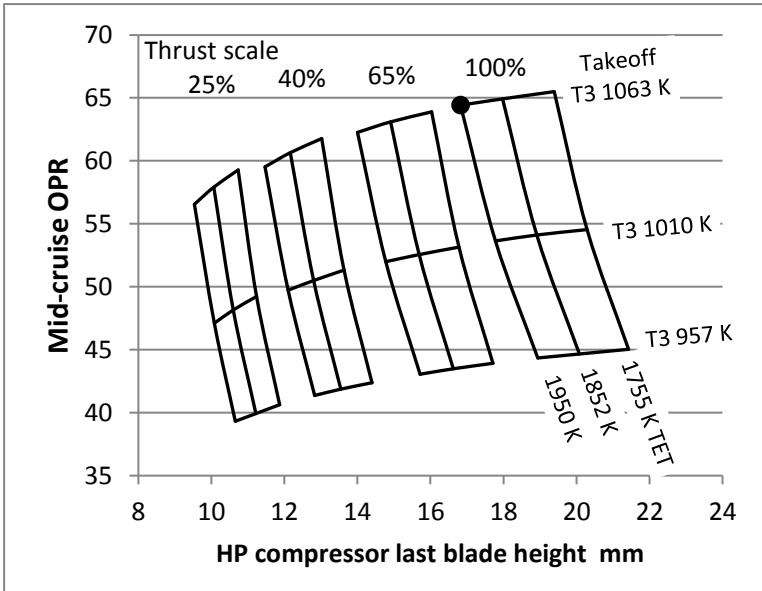

Figure 14 The effect on HP compressor blading and midcruise OPR of scaling the reference engine and designing it for different hot day takeoff temperature limits

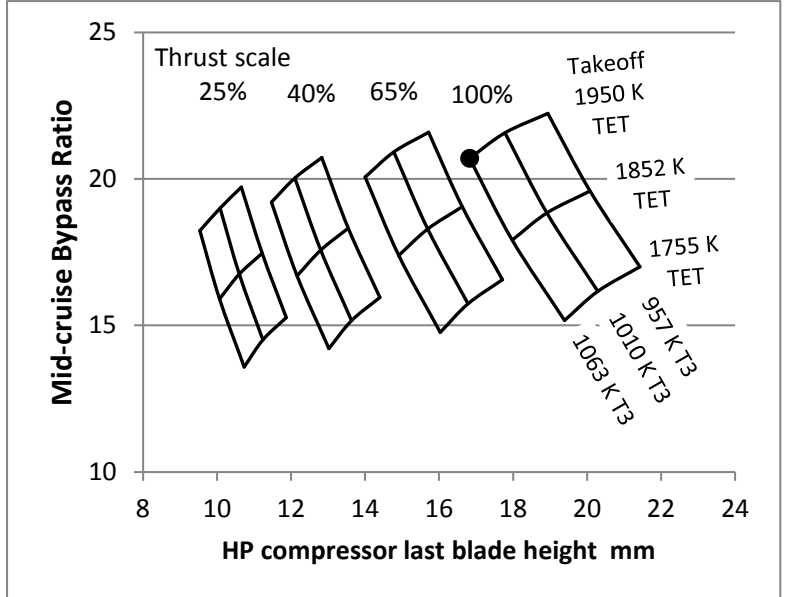

Figure 15 The effect on mid-cruise bypass ratio of scaling the reference engine and designing it for different hot day takeoff temperature limits for $\mathrm{T}_{3}$ and TET

\subsection{High OPR Intercooled Cycles}

Previous studies of intercooled turbofan engines have shown that positioning the intercooler relatively early in the overall compression system gives the best SFC. Thus all the high OPR intercooled engines in this study have high pressure ratio HP compressors driven by two-stage HP turbines. Intercooling enables engines to have increased OPR and core specific power relative to the reference turbofan cycle, but without the very high $\mathrm{T}_{3}$ temperatures that challenge mechanical design and $\mathrm{NO}_{\mathrm{x}}$ emissions. Increasing OPR and TET generally gives higher thermal efficiency, but because the HP compressor last blade height and efficiency reduce as design point OPR increases, there is an optimum OPR for best SFC and there are diminishing returns for increasing TET. In the current study, increases in max climb OPR of up to $60 \%$ are considered with 120 as the limiting OPR.

In these intercooled cycles most of the benefit from intercooling comes from having smaller core components that increase OPR and core specific power at a thrust. Intercooling enables this to be done without exceeding any cycle temperature limits. Overcooling the core flow at cruise does not improve thermal efficiency, but reducing the intercooler cold side cooling air mass flow at cruise and climb, relative to takeoff, significantly reduces the cold side pressure losses and so helps to improve overall cycle performance. The downside is that the engine runs hotter at cruise with potential impact on component life, but the $T_{3}$ levels are still generally much lower than for the non-intercooled engines, so this can compensate for the higher mid-cruise TET levels.

For the $100 \%$ thrust scale engine the highest permitted max climb OPR and TET give the best climb and cruise SFC. However, it seems that the improvement in mid-cruise SFC relative to the conventional reference engine is smaller than the improvement in max climb SFC. In order to minimise mid-cruise SFC, a parametric study investigated the trade-off between intercooler effectiveness, TET and OPR at the mid-cruise condition. Midcruise intercooler effectiveness is varied between $50 \%$ and $69 \%$. The results for two different engines with max climb design point pressure ratios of 75 and 120 are shown in Figs 16 and 17. Figure 16 shows how the midcruise OPR varies with intercooler effectiveness and TET, and Fig. 17 shows how the SFC varies. The highest max climb OPR cycles give the best max climb SFC, but mid-cruise SFC for the higher OPR cycles is improved by reducing off-design OPR and optimising intercooler effectiveness and TET. This also increases the midcruise bypass ratio by reducing the core mass flow.

The max climb design point cases in the scaling parametric study are run with the assumed limiting intercooler effectiveness of $75 \%$ and TET of $1890 \mathrm{~K}$, but with OPR levels ranging from 75 to 120 . The TET is limited to $1950 \mathrm{~K}$ for the hot day takeoff cases by adjusting the fan bypass section to LP compressor work-split.

The HP compressor last blade height is significantly reduced in the higher OPR intercooled engine cycles. This is costing these cycles $1-2 \%$ of HP compressor efficiency and $0.5-1.0 \%$ of HP turbine efficiency relative to the reference turbofan. The SFC levels of the intercooled engines are therefore several percentage points worse than they would have been had the component efficiencies not been reduced by the scaling-down of the core components relative to those in the non-intercooled engines.

Some intercooled cycles would seem to benefit from having HP compressor pressure ratios of 30 or more at max climb. However, the design of compressors with such high pressure ratios is difficult and likely to lead to reduced component efficiency. In this study the HP compressor pressure ratios are limited to 26 at top of climb. 


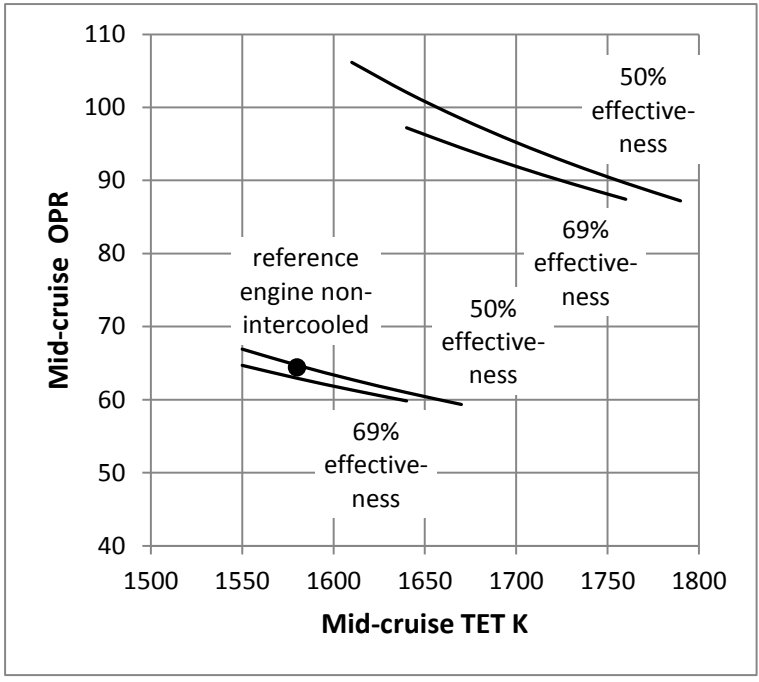

Figure 16 How mid-cruise OPR varies with TET and intercooler effectiveness for two different engines with 75 and 120 OPR at the max climb design point

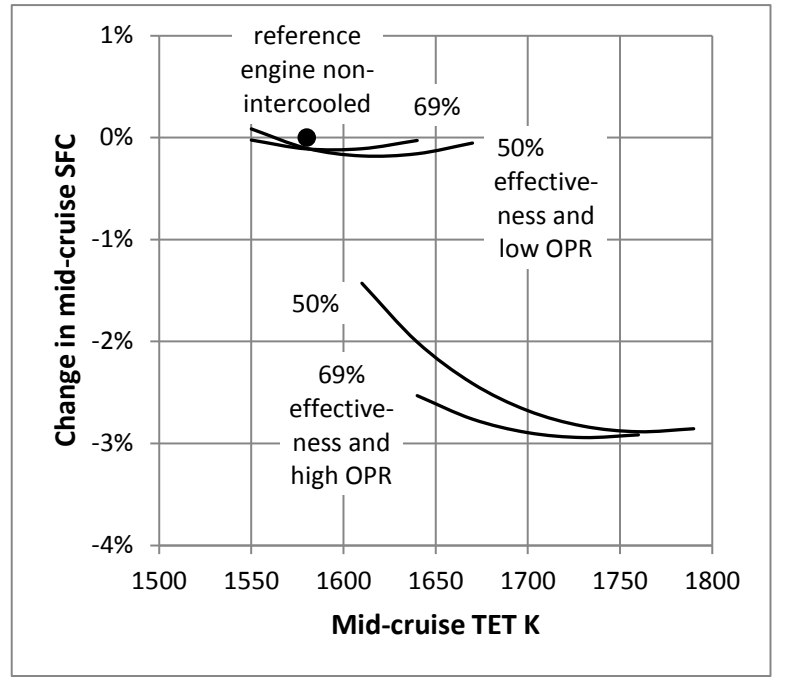

Figure 17 How mid-cruise SFC varies with TET and intercooler effectiveness for two different engines with 75 and 120 OPR at the max climb design point

The HP compressor pressure ratio typically falls to around 22-23 at takeoff and to 18-21 at mid-cruise. The generally lower cycle temperatures in the HP compressors of the intercooled engines (and the lower $\mathrm{T}_{3}$ and higher TET conventional cycle engines) result in more lightly loaded two-stage HP turbines. These turbines may therefore merit slightly higher efficiencies, but no credit has been taken for this in the current study.

\subsection{Scaling the Intercooled Engines}

The scaled intercooled engine cycles are run to the limiting max climb and max takeoff TET specified in table 3 . In this study the mid-cruise TET is varied in the range $1640 \mathrm{~K}$ to $1700 \mathrm{~K}$ and the intercooler mid-cruise effectiveness is varied in the range $50 \%$ to $69 \%$, with the higher values giving better SFC in engines with higher OPR at their max cruise design points. This is in line with the trend in Fig. 17. Increasing TET gives the best SFC, but for little penalty, the TET can be reduced by increasing OPR or intercooler effectiveness. In practice the optimum performance is likely to be obtained as much by optimising the cycle matching to maximise HP and LP compressor efficiencies, as by adjusting the amount of cooling air provided to the intercooler at cruise.

Figures 18 and 19 show how max climb SFC and mid-cruise SFC vary with OPR and thrust scale. The smaller core size intercooled engines are designed with $75,90,105$ or 120 OPR at max climb, whereas OPR for the conventional engines is limited by $\mathrm{T}_{3}$ as shown in Fig. 14. For the scaled intercooled engines, OPR rather than $\mathrm{T}_{3}$ has been varied. Figures 20 and 21 show the max climb and max takeoff $\mathrm{T}_{3}$ figures for the intercooled cycles are substantially lower than those for the conventional engines having the best SFC.

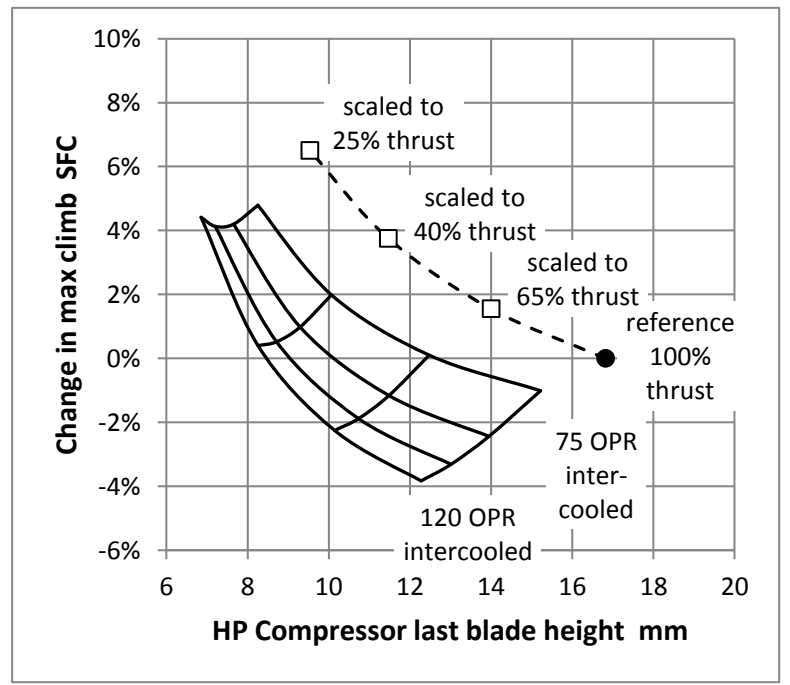

Figure 18 Effect of HP compressor last blade height and max climb OPR on max climb SFC for engines with $75 \%$ intercooler effectiveness $v$. the best conventional engines

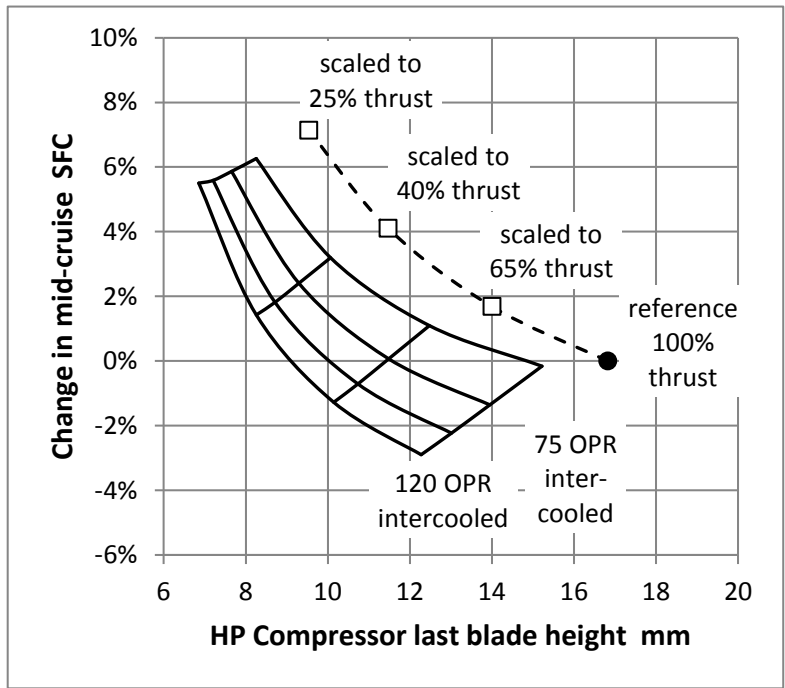

Figure 19 Improvements in mid-cruise SFC for intercooled engines from Fig. 18 with optimised mid-cruise intercooler effectiveness, OPR and TET v. the best conventional engines 


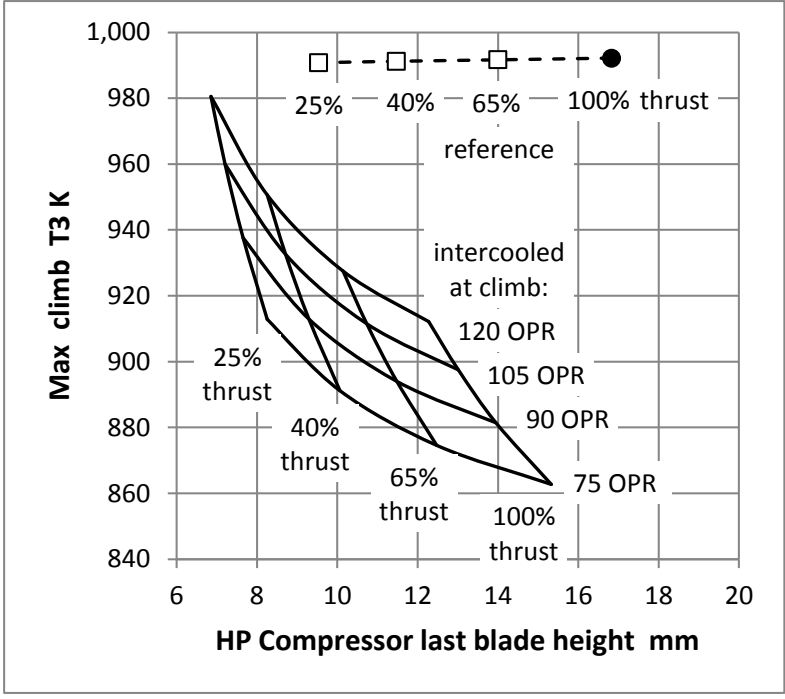

Figure 20 Max climb T3 for the conventional and intercooled engines from Fig. 18

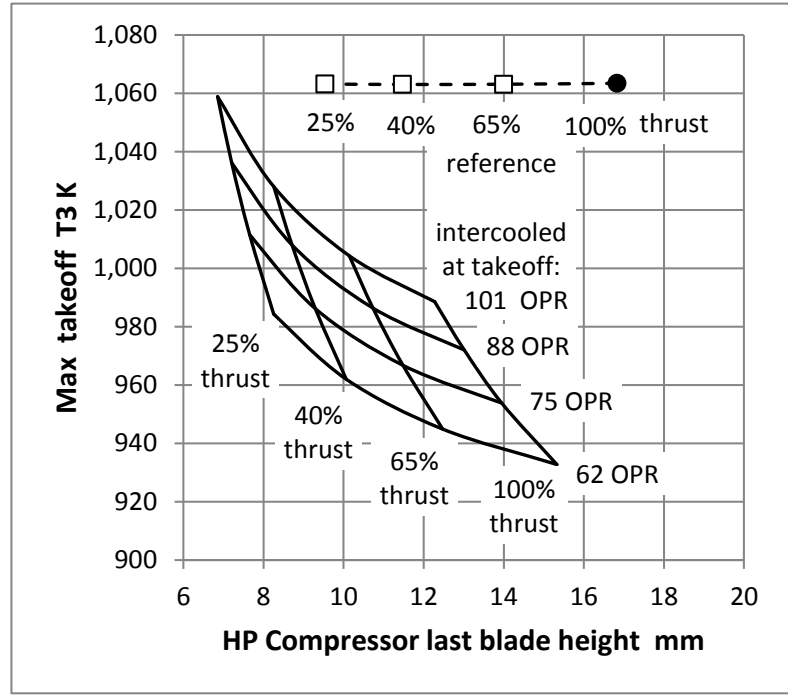

Figure 21 Max takeoff T3 for the conventional and intercooled engines from Fig. 18

Note $\mathrm{T}_{3}$ increases significantly at an OPR as the HP systems are scaled down. For the highest OPR and $25 \%$ thrust scale cases, $\mathrm{T}_{3}$ approaches the limits set for max climb and max takeoff in table 3 , but this cycle does not give the best max climb SFC. For the intercooled engines there is the option to reduce $\mathrm{T}_{3}$ and TET at the midcruise condition by increasing the intercooler effectiveness and core mass flow, but at the expense a small increase in SFC. A summary of the results for the conventional and intercooled engine cycles found to have the best combination of max climb and mid-cruise SFC at each thrust scale is given in table 6.

Table 6

Performance Comparison for Selected Scaled 2050 Reference and 2050 Intercooled Turbofan Engines

\section{Brayton Cycle Turbofans}

Thrust Scale:

\section{HP compressor exit}

blade height (mm)

Mid-cruise performance

Thrust (kN)

OPR

Bypass ratio

SFC (mg/N.s)

Relative SFC

Max climb performance

OPR

SFC (mg/N.s)

Relative SFC

$\begin{array}{cccccccc}\mathbf{1 0 0 \%} & \mathbf{6 5 \%} & \mathbf{4 0 \%} & \mathbf{2 5 \%} & \mathbf{1 0 0 \%} & \mathbf{6 5 \%} & \mathbf{4 0 \%} & \mathbf{2 5 \%} \\ 16.8 & 14.0 & 11.5 & 9.5 & 12.3 & 10.1 & 8.3 & 7.2 \\ & & & & & & & \\ 49.0 & 31.8 & 19.6 & 12.2 & 49.0 & 31.8 & 19.6 & 12.2 \\ 64.4 & 62.3 & 59.5 & 56.5 & 91.9 & 91.9 & 92.0 & 83.5 \\ 20.7 & 20.0 & 19.2 & 18.2 & 27.6 & 26.4 & 24.8 & 22.1 \\ 12.88 & 13.10 & 13.41 & 13.80 & 12.51 & 12.72 & 13.07 & 13.60 \\ \text { datum } & +1.7 \% & +4.1 \% & +7.1 \% & -2.9 \% & -1.3 \% & +1.4 \% & +5.6 \% \\ & & & & & & & \\ 75.0 & 72.4 & 69.0 & 65.5 & 120 & 120 & 120 & 105 \\ 13.91 & 14.13 & 14.43 & 14.81 & 13.38 & 13.60 & 13.98 & 14.49 \\ \text { datum } & +1.5 \% & +3.8 \% & +6.5 \% & -3.8 \% & -2.2 \% & +0.5 \% & +4.1 \%\end{array}$

\subsection{CONCLUSIONS}

Design point trade studies confirm that the conventional reference turbofan engine cycle for 2050 entry into service is close to optimum for the initial long-range aircraft thrust requirements, given the takeoff temperature limits that should enable low $\mathrm{NO}_{\mathrm{x}}$ emissions to be achieved with lean combustion. However, future aircraft are expected to need less thrust. Hence engine performance is modelled for a wide range of thrust scales. To focus on core thermal efficiency, all engines are modelled with the same low $72 \mathrm{~m} / \mathrm{s}$ mid-cruise specific thrust giving bypass ratios from 14 to 22 for conventional engines and up to 28 for intercooled engines.

Scaling down is shown to have significant effects on engine component efficiencies and on turbine cooling air requirements. To model major effects on core performance, the HP compressor and turbine efficiencies are adjusted for variations in HP compressor last stage blade height. The cooled cooling air mass flows are also varied with core mass flow and TET. The non-intercooled engines are subject to limits on HP compressor delivery temperature, so as compression efficiency reduces in scaled-down engines, OPR and booster pressure ratio also reduce. Scaling to $25 \%$ of the original thrust and half the original fan diameter could reduce OPR by about $13 \%$, increasing SFC by about $7 \%$ and reducing thermal efficiency by $6.5 \%$. Also intercooling could 
reduce mid-cruise SFC by about $3 \%$ for the larger engines and by $2 \%$ for the smaller engines, and reduce max climb SFC by nearly $4 \%$ in the larger engines and by $2 \%$ in the smaller engines.

This study considers the potential of future cycles to achieve high overall efficiency and low SFC, but with no mechanical design or engine operability assessments at this stage. Axi-centrifugal HP compressors might be substituted for all-axial compressors in smallest cores. The cycles with the lowest mid-cruise SFC may not be the overall optimum cycles, because geared fan engines with slightly lower OPR and smaller core mass flows are likely to be lighter. Practical considerations mean that the fuel burn optimum and economic optimum designs are likely to back-off from cycles with the highest OPR and lowest SFC, made possible by having cooled cooling air and/or intercooling. This applies particularly to the smaller thrust-scale engines. Very high OPR cycles pose particular design challenges including, more highly loaded bearings, compressors and turbines needing extra stages, and more variable stages on each compressor. Without further research and innovative design these challenges could prevent the ambitious 2050 SFC targets being achieved. However intercooling and cooled cooling air technologies would provide the core turbomachinery with more benign thermal environments that should help with other issues including component life, heat to oil, and tip clearance control.

This study provides a foundation for the assessment of SFC and fuel burn in ongoing ULTIMATE studies of more complex cycles featuring additional combinations of advanced technologies.

\section{ACKNOWLEDGMENTS}

This project has received funding from the European Union's Horizon 2020 research and innovation programme under Grant Agreement No. 633436. The authors are grateful to Cranfield University, Chalmers University of Technology, and Rolls-Royce plc for permission to publish this paper. Figures 1 and 3 are reproduced courtesy of the NEWAC Consortium and Rolls-Royce plc.

\section{REFERENCES}

1. PARKeR R. Challenges of Advanced Propulsion Systems Development for Future Civil Air Transport, General Lecture 1, ICAS-2014-0.2 ICAS Conference 2014, St. Petersburg, Russia, 9 September 2014.

2. GRÖNSTEDT T. et al. Ultra Low Emissions Technology Innovations for Mid-century Aircraft Turbine Engines, GT2016-56123, ASME Turbo Expo 2016, Seoul, Korea, June 2016.

\section{ULTIMATE project website: http://www.ultimate.aero}

4. ACARE. Realising Europe's vision for aviation, Strategic Research \& Innovation Agenda, Volume 1, Advisory Council for Aviation Research and Innovation in Europe, 2012.

5. ROLT A. and BAKER N. Intercooled Turbofan Engine Design and Technology Research in the EU Framework 6 NEWAC Programme, ISABE-2009-1278, ISABE 2009 Conference, Montreal, Canada, 2009.

6. Rolt A. and KyPRIANIDIS K. Assessment of New Aeroengine Core Concepts and Technologies in the EU Framework 6 NEWAC Programme, ICAS-2010-408, ICAS Conference 2010, Nice, France, September 2010.

7. KYPRIANIDIS K. and ROLT A. On the Optimisation of a Geared Fan Intercooled Core Engine Design, Journal of Engineering for Gas Turbines and Power, 2015, Vol. 137(4) 041201.

8. CAMILLERI W. et al. Performance characteristics and optimisation of a geared intercooled reverse flow core engine, Proc IMechE Part G; Journal of Aerospace Engineering, 2015, Vol. 229(2) 269-279.

9. CAMILLERI W. et al. Concept description and assessment of the main features of a geared intercooled reversed flow core engine, Proc IMechE Part G; Journal of Aerospace Engineering, 2015, Vol. 229(9) 1631-1639.

10. ANSELMI E. et al. Assessment of the low pressure turbine exhaust design challenges in a Geared Intercooled Reversed Flow Core Engine, ISABE-2015-20200, ISABE 2015 Conference, Phoenix, USA, October 2015.

11. ZhaO X. and GRÖNSTEDT T. Conceptual Design of a two-pass cross-flow aeroengine intercooler, Proc IMechE Part G; Journal of Aerospace Engineering, 2015, Vol. 229(11) 2006-2023.

12. WAlsh P. and Fletcher P. Gas Turbine Performance, second edition 2004, Blackwell Science, ISBN 97806320064342 . 
2017-06-08

\section{Scale effects on conventional and intercooled turbofan engine performance}

Rolt, Andrew Martin

Cambridge University Press

Rolt A, Sethi V, Jacob F, et al., (2017) Scale effects on conventional and intercooled turbofan engine performance. Aeronautical Journal, Volume 121, Issue 1242, August 2017, pp. 1162-1185 http://dx.doi.org/10.1017/aer.2017.38

Downloaded from Cranfield Library Services E-Repository 